\title{
Short-term postoperative discomfort in patients receiving flapless contra open implant surgery
}

\author{
Alexander Aizenberg ${ }^{1}$, Jesper Jansson ${ }^{1}$, Peter Abrahamsson ${ }^{2}$ \\ ${ }^{1}$ Department of Oral and Maxillofacial Surgery and Oral Medicine, Faculty of Odontology, Malmö University, Malmö, Sweden \\ ${ }^{2}$ Maxillofacial Unit, Halmstad Hospital, Halmstad, Sweden \\ Email: alex@alinks.se, jesper.jansson@gmail.com, peter.abrahamsson@regionhalland.se
}

Received 11 May 2013; revised 12 June 2013; accepted 10 July 2013

Copyright (C) 2013 Alexander Aizenberg et al. This is an open access article distributed under the Creative Commons Attribution License, which permits unrestricted use, distribution, and reproduction in any medium, provided the original work is properly cited.

\begin{abstract}
Purpose: The aim of this pilot study was to evaluate subjective and objective findings on short-term postoperative discomfort in patients receiving flapless implant surgery compared to traditional open flap surgery. Materials and Methods: A two-centre, prospective survey study was conducted, using a customized questionnaire. Between December 2010 and January 2012, 20 patients were consecutively included. Eleven received conventional open-flap surgery and nine received flapless surgery. Inflammatory signs, analgesic consumption and sleeping difficulties were evaluated up to seven days postoperatively. A clinical examination was made one week postoperatively. Results: Significantly less experienced swelling was noted 24 hours after flapless surgery compared to open flap surgery for patients receiving four implants or more, and at three days postoperatively for patients receiving single implants. No difference concerning sleeping difficulties, pain or analgesic consumption was found. Clinical examination one week postoperatively showed no differences in wound gaps, redness of the mucosa, or presence of pus between the groups. Conclusions: In conclusion, flapless surgery seems to have a limited effect on postoperative comfort and short-term postoperative signs of soft tissue healing compared to open flap surgery. There is a need for larger randomized trials for evaluating differences in postoperative discomfort between the two surgical techniques.
\end{abstract}

Keywords: Postoperative Discomfort; Flapless Surgery; Guided Implant Surgery

\section{INTRODUCTION}

To enable the insertion of a dental implant, open flap surgery has been a standard technique. Conventional implant surgery involves transmucosal incision and reflection of a mucoperiosteal flap, followed by preparation of an implant socket in the alveolar bone. A dental implant can then be inserted and the flap can be sutured back into its original position [1]. However, this method can lead to some post-operative discomforts. Both physical and mental strains are commonly associated with conventional implant surgery [2-4]. Inflammatory signs such as pain, swelling and bleeding are normally seen postoperatively [5].

An alternative to a conventional flap elevation is the minimally invasive, flapless approach. Clinical studies have revealed that implants can be successfully placed with a flapless technique [6-9]. The treatment time and patient discomforts are reduced compared to traditional implant surgery $[8,10,11]$. Blood supply to the periosteum is preserved and sutures become superfluous $[5,12$, 13]. A histological study has shown significantly higher amount of blood vessels in the peri-implant mucosa three months after insertion of a dental implant in flapless surgery compared to flap elevation. Furthermore, no signs of inflammation in the mucosa surrounding such implants were seen [14].

Flapless surgery is an advanced technique that requires considerable surgical experience and extensive knowledge of the underlying tissue anatomy [15]. The main disadvantages are the inability to visualize anatomic landmarks, increased risk of misplaced implants, risk of over heating and the impossibility to manipulate the soft tissue $[5,15]$.

To overcome some of the problems encountered in flapless surgery, a 3D planning software [16], based on a cone beam computed tomography (CBCT) or regular computed tomography (CT) scan, has been developed. This method has been defined as computer-assisted surgery and includes the use of a surgical template $[5,17]$. 
Current studies on computer-assisted surgery show a high level of implant survival (91\% - 100\%) after 12 - 60 months [18], but there are no long-term follow-ups [17]. The accuracy of the available systems has not yet been perfected [18]. An in vitro study has shown an increased heat generation during drilling when a surgical template is used [19].

There is a need of further research in post-operative comfort associated with flapless and computer guided implant surgery [17]. Computer-assisted surgery is still considered to be an experimental treatment and constitutes an increased cost for the patient. It is therefore desirable to further investigate what the benefits are at a patient level.

The aim of this pilot study was to evaluate subjective and objective findings on short-term postoperative discomfort in patients receiving flapless implant surgery compared to traditional open surgery. The working hypothesis was that using flapless technique leads to less short-term postoperative discomfort.

\section{METHODS}

\subsection{Study Design}

The study took place from December 2010 to January 2012 at the maxillofacial unit at the Halland Hospital, Halmstad, and in a private clinic specialized in implant dentistry, located in Ytterby, Sweden. One surgeon was an experienced maxillofacial specialist and the other was an experienced DDS with high level of knowledge in implant dentistry.

Patients scheduled for flapless implant surgery who met the inclusion/exclusion criteria (Table 1) were asked to participate in the study. These patients were matched with patients referred for conventional open flap implant

Table 1. Inclusion and exclusion criteria.

\begin{tabular}{cc}
\hline Inclusion & Exclusion \\
\hline $\begin{array}{c}\text { Patient } \geq 18 \text { years } \\
\text { Implant treatment is } \\
\text { Patient consent available }\end{array}$ & Implant treatment of the mandible \\
& Direct placement of implant \\
& Pone augmentation needed \\
& Immunocompromised patient \\
& Drug or alcohol abuse \\
& Radiation of head/neck-region \\
& Psychiatric disease \\
& Uncontrolled diabetes \\
& Completed cytostatic treatment \\
& Bisphosphonate treatment \\
\hline
\end{tabular}

treatment. They were matched in number of implants and position of implants. Taking part in the study was completely voluntary, anonymous and did not affect the choice of treatment. Informed consent was obtained from all participants. The patient selection was consecutive. The ethical board at the Faculty of Odontology, Malmö University, issued ethical approval.

A total of 20 patients were included in the study (mean age 56.9 years, $S D$ 18.75). Six patients (mean age 51.8 years, $S D$ 19.64) received single implants installed with conventional technique and five (mean age 40.8 years, $S D$ 16.45) received single implants installed with flapless technique. Five patients (mean age 68.0 years, SD 8.43) received four implants or more installed with conventional technique and four (mean age 71.0 years, SD 13.21) received four implants or more installed with flapless technique. No significant differences regarding gender and age were seen between the groups.

\subsection{Surgical Methods}

Computer-assisted implant surgery in this study included the following steps:

A clinical and radiographic examination was made; including panoramic X-ray to ensure the anatomical and pathophysiological conditions of the jaws. Impressions for study casts were taken together with a stable index. A dental technician manufactured working models that were used to make a diagnostic tooth set-up. When the tooth set-up was accepted, a radiographic guide in clear acrylic was made. This guide was provided with radiopaque reference markers. A double CT-scan protocol was used. First the patient was scanned with the radiological guide and index in place. Thereafter, the guide alone was scanned. In the planning software the two scans were overlaid to distinguish soft tissue from the guide material, as they have similar radio-density. Data from the scan was processed in the planning software. Virtual implants were then placed with consideration to anatomical structures as well as depth, angulation and position of the fixture.

The surgical guide was manufactured in hard acrylic with sleeves for the implant drills. The guide was positioned using the original index and stabilized with the help of anchor pins. In this stage, the operator transferred the planned implant position, depth and angle from the software to the actual mouth. To penetrate the mucosa a tissue punch was used.

In this study NobelClinican ${ }^{\mathrm{TM}}$ solution (Nobel Biocare, Yorba Linda, CA) was used for planning and planning conducted by the operating surgeon. A tissue punch was used for all flapless incisions.

In the open flap surgery group a mucoperiosteal flap was raised to expose the alveolar bone. The implant sockets were prepared and implants installed in accor- 
dance to the manufacturers drill protocol. After implant installation the flap was sutured using Vicryl 4-0 sutures (Ethicon Inc., Somerville, NJ).

Surgery was conducted using local anaesthesia (Xylocain $^{\circledR}$ Dental Adrenalin, Dentsply Pharmaceutical). Prescription-free NSAID and Paracetamol were used for postoperative pain relief when needed. All patients in the trial received antibiotics per os according to the clinics standardized protocol.

\subsection{Postoperative Evaluation}

Patients that agreed to take part in the study received a multiple-choice form. They were asked to evaluate subjective post-operative discomfort and sleeping difficulties 24 hours, three days and seven days postoperatively. Consumption of analgesics was recorded at the same intervals. A numerical rating scale (NRS) was used to evaluate pain (Figure 1).

\title{
Questionnaire
}

1. I am a: $\square$ Woman $\square$ Man

2. I was born 19

3. Did you experience swelling in the operated area 24 hours after surgery?

\author{
No, not at all \\ Some swelling \\ A lot of swelling
}

4. Did you experience bleeding from the operated area 24 hours after surgery?

No, not at all

Some bleeding

A lot of bleeding

5. Rate your pain 24 hours after the procedure:

\begin{tabular}{|c|c|c|c|c|c|c|c|c|c|c|}
\hline$\underline{\mathbf{0}}$ & $\underline{1}$ & $\underline{\mathbf{2}}$ & $\underline{\mathbf{3}}$ & $\underline{4}$ & $\underline{5}$ & $\underline{6}$ & $\underline{7}$ & $\underline{8}$ & $\underline{9}$ & $\underline{10}$ \\
\hline $\begin{array}{l}\overline{\text { No }} \\
\text { pain }\end{array}$ & & & & & & & & & & $\begin{array}{l}\text { Worst } \\
\text { pain } \\
\text { imaginable }\end{array}$ \\
\hline
\end{tabular}

6.

Did you use any pain killers 24 hours after surgery?

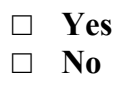

Amount:

Type:

7. Did you experience difficulty sleeping 24 hours after surgery?

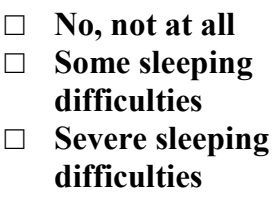

\section{Thank you for participating!}

Figure 1. Questionnaire used by patient at 24 hours, three and seven days postoperatively in accordance. 
All patients were examined 1 week postoperatively by the operating surgeon according to a standardized form (Figure 2). Patient and dentist forms were matched using a code system.

\subsection{Statistical Methods}

Statistical analysis was conducted using SPSS 20.0 (SPSS, Inc., Chicago, IL). Due to the small sample size
Fishers' exact test was used for categorical variables and a non-parametric statistical hypothesis test (Mann-Whitney $U$-test) for numerical variables. Level of significance was set at $p<0.05$.

\section{RESULTS}

\subsection{Single Implants}

No significant difference in experienced postoperative

\section{Dentist form}

This form is filled out by the dentist at the examination one week after surgery. Enter the number from the patient questionnaire in the upper right corner.

1. Which method was used for implant surgery? $\square$ Open flap $\square$ Flapless

2. $\square$ Which jaw was treated? $\square$ Maxilla $\square$ Mandible $\square$ Both

3. How many fixtures were installed?

4. In which positions were the fixtures placed?

5.

Which type of antibiotic was used and what dose?

Type:

Dose:

$\square \quad$ No antibiotics

6. Wound gaps?

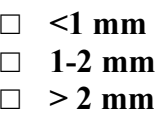

7. Redness of the mucosa?

\section{Less than $25 \%$ of the surgical area $25-50 \%$ of the surgical area More than $50 \%$ of the surgical area}

8. Presence of pus in the surgical area?

Figure 2. Form filled out by dentist one week postoperatively. 
swelling was reported between the groups at 24 hours and seven days after installation but at three days a significant difference was noted $(p<0.05$, Table 2). No differences in NRS scores for pain were seen at any interval (Table 3). After 24 hours 2/6 patients in the open flap surgery group and $1 / 5$ patients in the flapless surgery group reported some bleeding. Three and seven days postoperatively no bleeding was reported in any of the groups. No significant differences were seen.

After 24 hours $5 / 6$ patients in the open flap surgery group and 2/5 in the flapless group consumed analgesics. After three days none of the patients consumed analgesics. No significant difference was seen between the groups.

Two out of five patients in the flapless group reported some sleeping difficulties after 24 hours, but none after three and seven days. In the open flap group 1/6 patients reported some sleeping difficulties at 24 hours, after three days $1 / 6$ patients reported some sleeping difficulties and at seven days no patients experienced any sleeping difficulties. No statistical difference was found at any interval. No correlation between level of pain and sleeping difficulties was seen. Two patients reported paresthesia seven days after surgery and both had single implants installed in the anterior region using flap elevation.

Table 2. Swelling.

\begin{tabular}{|c|c|c|c|}
\hline Method & Swelling $24 \mathrm{~h}$ & Swelling 3 days & Swelling 7 days \\
\hline $\begin{array}{c}\text { Flapless } \\
{[\mathrm{n}=5]}\end{array}$ & $\begin{array}{c}\text { None }=40 \% \\
{[\mathrm{n}=2]} \\
\text { Some }=60 \% \\
{[\mathrm{n}=3]} \\
\text { A lot }=0 \% \\
{[\mathrm{n}=0]}\end{array}$ & $\begin{array}{c}\text { None }=100 \% \\
{[\mathrm{n}=5]} \\
\text { Some }=0 \% \\
{[\mathrm{n}=0]} \\
\text { A lot }=0 \% \\
{[\mathrm{n}=0]}\end{array}$ & $\begin{array}{c}\text { None }=100 \% \\
{[\mathrm{n}=5]} \\
\text { Some }=0 \% \\
{[\mathrm{n}=0]} \\
\text { A lot }=0 \% \\
{[\mathrm{n}=0]}\end{array}$ \\
\hline $\begin{array}{l}\text { Open flap } \\
{[\mathrm{n}=6]}\end{array}$ & $\begin{array}{c}\text { None }=0 \% \\
{[n=0]} \\
\text { Some }=66.7 \% \\
{[n=4]} \\
\text { A lot }=33.3 \% \\
{[n=2]}\end{array}$ & $\begin{array}{c}\text { None }=16.7 \% \\
{[\mathrm{n}=1]} \\
\text { Some }=83.3 \% \\
{[\mathrm{n}=5]} \\
\text { A lot }=0 \% \\
{[\mathrm{n}=0]}\end{array}$ & $\begin{array}{c}\text { None }=83.3 \% \\
{[\mathrm{n}=5]} \\
\text { Some }=16.7 \% \\
{[\mathrm{n}=1]} \\
\text { A lot }=0 \% \\
{[\mathrm{n}=0]}\end{array}$ \\
\hline$p$-value & 0.212 & 0.015 & 1.0 \\
\hline
\end{tabular}

Experienced swelling at different intervals for patients receiving single implants.

Table 3. Pain.

\begin{tabular}{cccc}
\hline Method & Pain 24 h & Pain 3 days & Pain 7 days \\
\hline Flapless [n=5] & $1[0-4]$ & $0[0-2]$ & $0[0-2]$ \\
Open flap [n=6] & $3[0-7]$ & $0[0-2]$ & $0[0-1]$ \\
$\boldsymbol{p}$-value & 0.404 & 0.840 & 0.521 \\
\hline
\end{tabular}

Median values for pain [NRS] at different intervals [min-max] for patients receiving single implants.

\subsection{Four Implants or More}

Significant difference between the groups in experienced swelling was reported at 24 hours but not at three or seven days ( $p<0.05$, Table 4). One out of five patients in the open flap group experienced bleeding at 24 hours and at three days. No significant differences were seen between the groups. No differences in NRS scores for pain were seen at any interval (Table 5). After 24 hours $4 / 5$ patients in the open flap surgery group and $2 / 4$ in the flapless group consumed analgesics. After three days none of the patients consumed analgesics. Two out of five patients in the open surgery group reported some sleeping difficulties after 24 hours, $1 / 5$ after three days but none after seven days. In the flapless group none of the patients reported sleeping difficulties. No paresthesia was reported at seven days.

\subsection{Clinical Examination}

Clinical examination one week postoperatively showed no statistical differences in wound gaps, redness of the mucosa or presence of pus between any groups. The majority of the patients had redness of the mucosa $<25 \%$ of the operated area, wound gaps $<1 \mathrm{~mm}$ and none had presence of pus.

Table 4. Swelling.

\begin{tabular}{|c|c|c|c|}
\hline Method & Swelling 24 h & Swelling 3 days & Swelling 7 days \\
\hline $\begin{array}{c}\text { Flapless } \\
{[\mathrm{n}=4]}\end{array}$ & $\begin{array}{c}\text { None }=50 \% \\
{[\mathrm{n}=2]} \\
\text { Some }=50 \% \\
{[\mathrm{n}=2]} \\
\text { A lot }=0 \% \\
{[\mathrm{n}=0]}\end{array}$ & $\begin{array}{c}\text { None }=75 \% \\
{[\mathrm{n}=3]} \\
\text { Some }=25 \% \\
{[\mathrm{n}=1]} \\
\text { A lot }=0 \% \\
{[\mathrm{n}=0]}\end{array}$ & $\begin{array}{c}\text { None }=75 \% \\
{[\mathrm{n}=3]} \\
\text { Some }=25 \% \\
{[\mathrm{n}=1]} \\
\text { A lot }=0 \% \\
{[\mathrm{n}=0]}\end{array}$ \\
\hline $\begin{array}{l}\text { Open flap } \\
{[\mathrm{n}=5]}\end{array}$ & $\begin{array}{c}\text { None }=0 \% \\
{[\mathrm{n}=0]} \\
\text { Some }=20 \% \\
{[\mathrm{n}=1]} \\
\text { A lot }=80 \% \\
{[\mathrm{n}=4]}\end{array}$ & $\begin{array}{c}\text { None }=0 \% \\
{[\mathrm{n}=0]} \\
\text { Some }=60 \% \\
{[\mathrm{n}=3]} \\
\text { A lot }=40 \% \\
{[\mathrm{n}=4]}\end{array}$ & $\begin{array}{c}\text { None }=100 \% \\
{[\mathrm{n}=5]} \\
\text { Some }=0 \% \\
{[\mathrm{n}=0]} \\
\text { A lot }=0 \% \\
{[\mathrm{n}=0]}\end{array}$ \\
\hline$p$-value & 0.048 & 0.079 & 0.264 \\
\hline
\end{tabular}

Experienced swelling at different intervals for patients receiving $\geq 4 \mathrm{im}$ plants.

Table 5. Pain.

\begin{tabular}{cccc}
\hline Method & Pain 24 h & Pain 3 days & Pain $\mathbf{7}$ days \\
\hline $\begin{array}{c}\text { Flapless } \\
{[\mathrm{n}=4]}\end{array}$ & $1[0-3]$ & $1[0-2]$ & $0[0-2]$ \\
$\begin{array}{c}\text { Open flap } \\
{[\mathrm{n}=5]}\end{array}$ & $4[1-5]$ & $2[0-5]$ & $0[0-1]$ \\
$\boldsymbol{p}$-value & 0.59 & 0.592 & 0.737 \\
\hline
\end{tabular}

Median values for pain [NRS] at different intervals [min-max] for patients receiving $\geq 4$ implants. 


\section{DISCUSSION}

In this study a tendency to short-term benefits in postoperative comfort was seen in the flapless surgery group as swelling was significantly less reported in this group. No significant differences could be seen regarding pain or analgesic consumption. These latter findings do not correlate with results reported by Fortin et al., [20] where the patients receiving flapless surgery experienced less pain up to two days and consumed less analgesic up to three days, and Nkenke et al. [21] who found a significant reduction in pain and swelling for patients receiving flapless surgery up to seven days postoperatively. Swelling, in that study, was measured with an optical 3D image system. Different ways to register pain (VAS-scale in the two studies above and NRS in this study) as well as different statistical tests make comparison of the results somewhat uncertain. It cannot be excluded that the small sample size in the present study could have an influence on the divergent findings compared to other studies.

It should also be noted that pain could arise from factors not associated with the surgical method itself, such as surgical time and the patients' fear, stress and anxiety levels [20]. In third molar surgery extended operating time is correlated to increased postoperative pain [21-23] and complications such as paresthesia [24,25]; this might also be valid for implant surgery. In the present study surgical time was not measured, but increased amount of installed implants could be expected to result in extended surgical time. Despite this, pain levels were not significantly higher in patients receiving four implants or more compared to those receiving a single implant. An explanation might be the observation by Lindeboom et al. that no gain in time was measured when computer-assisted, flapless surgery was used [26].

Clinical examination one week postoperatively showed no statistical difference in wound gap, redness of the mucosa or presence of pus between groups and the observed changes were discrete, indicating that the advantage of flapless surgery contra open flap surgery for this reason can be questioned.

Patients in this study were allocated into the different groups as they were referred to the clinics. Patients referred for flapless surgery formed one group and patients referred for conventional surgery formed the other group. Patients in both groups were matched according to implant position and number of implants. It would have been desirable to randomize the patients into the two different groups. However, as the patients had to pay an additional cost for (computer-assisted) flapless surgery and not all patients were willing to do this, a randomization was not possible to perform.

In this study 20 patients participated. The low number of individuals can be contributed to the novelty of this treatment method and the higher cost of flapless implant surgery in combination with computer guided surgery. Still, significant differences were found in some areas. It would be desirable to increase the sample size to be able to detect smaller differences and obtain more reliable results.

Two patients in the open flap surgery group [single implant] reported paresthesia one week post-operatively. Temporary paresthesia has been shown to be a relatively common complication following implant surgery, especially in the mandible [27,28]. It can result from poor flap design, performing terminal block of the inferior alveolar nerve and during osteotomy preparation [27]. The paresthesia is often reversible and the incidence reported varies between $6.5 \%$ - 36\% [28-30]. The sensation often returns within four months and beyond [29]. The use of computer assisted implant surgery in combination with flapless technique may reduce the risk of nerve injury. It is not possible to know if the paresthesias reported in this study are reversible since the follow up time was limited to one week.

All patients in this study received antibiotics nevertheless there is currently no consensus regarding the use of antibiotics in implant dentistry [31] and there are no studies that evaluate the effect of antibiotics on postoperative discomfort in implant surgery. In third molar surgery postoperative pain was not reduced when using antibiotics [32,33].

This study shows that the main advantage of using flapless surgery is less postoperative swelling. This is to be expected since flapless surgery is less traumatizing to the soft tissue. No other benefits were found on a patient level. Still, maintaining blood supply to the periosteum is a major benefit since it potentially minimizes the risk of loosing bone height. The major disadvantages of flapless implant surgery can be avoided by using a computer assisted approach, yet this method also has some weaknesses. These include risk of overheating and inability to visualize anatomical landmarks. Computer assisted implant surgery is also an expensive treatment.

\section{CONCLUSION}

This pilot study indicates that flapless surgery compared to open flap surgery can lead to less postoperative swelling while no difference is seen regarding pain or postoperative bleeding. However, randomized studies based on larger sample sizes with focus on quality of life effects, including a cost-benefit analysis are required because of the considerably increased cost for the patient receiving flapless surgery.

\section{ACKNOWLEDGEMENTS}

We would like to thank Per-Erik Isberg and Björn Söderfeldt for valu- 
able help with questionnaire design and statistical analysis.

\section{REFERENCES}

[1] Branemark, P.I., Hansson, B.O., Adell, R., Breine, U., Lindstrom, J., Hallen, O., et al. (1977) Osseointegrated implants in the treatment of the edentulous jaw. Experience from a 10-year period. Scandinavian Journal of Plastic and Reconstructive Surgery Supplementum, 16, 1-132.

[2] Al-Khabbaz, A.K., Griffin, T.J. and Al-Shammari, K.F. (2007) Assessment of pain associated with the surgical placement of dental implants. Journal of Periodontology, 78, 239-246. doi:10.1902/jop.2007.060032

[3] Brand, H.S., Gortzak, R.A., Palmer-Bouva, C.C., Abraham, R.E. and Abraham-Inpijn, L. (1995) Cardiovascular and neuroendocrine responses during acute stress induced by different types of dental treatment. International Dental Journal, 45, 45-48.

[4] Hashem, A.A., Claffey, N.M. and O'Connell, B. (2006) Pain and anxiety following the placement of dental implants. The International Journal of Oral \& Maxillofacial Implants, 21, 943-950.

[5] Komiyama, A. (2010) Evaluation of computer-assisted virtual treatment planning and template-guided surgery in dental implant treatment. Larserics Digital Print AB, Sundbyberg, pp. 1-68.

[6] Campelo, L.D. and Camara, J.R. (2002) Flapless implant surgery: A 10-year clinical retrospective analysis. The International Journal of Oral \& Maxillofacial Implants, 17, 271-276.

[7] Komiyama, A., Klinge, B. and Hultin, M. (2008) Treatment outcome of immediately loaded implants installed in edentulous jaws following computer-assisted virtual treatment planning and flapless surgery. Clinical Oral Implants Research, 19, 677-685. doi:10.1111/j.1600-0501.2008.01538.x

[8] Cannizzaro, G., Leone, M., Consolo, U., Ferri, V. and Esposito, M. (2008) Immediate functional loading of implants placed with flapless surgery versus conventional implants in partially edentulous patients: A 3-year randomized controlled clinical trial. International Journal of Oral \& Maxillofacial Implants, 23, 867-875.

[9] Malo, P. and Nobre, M. (2008) Flap vs. flapless surgical techniques at immediate implant function in predominantly soft bone for rehabilitation of partial edentulism: A prospective cohort study with follow-up of 1 year. European Journal of Oral Implantology, 1, 293-304.

[10] Van Steenberghe, D., Glauser, R., Blomback, U., Andersson, M., Schutyser, F., Pettersson, A., et al. (2005) A computed tomographic scan-derived customized surgical template and fixed prosthesis for flapless surgery and immediate loading of implants in fully edentulous maxillae: A prospective multicenter study. Clinical Implant Dentistry and Related Research, 7, S111-S120. doi:10.1111/j.1708-8208.2005.tb00083.x

[11] Ozan, O., Turkyilmaz, I. and Yilmaz, B. (2007) A preliminary report of patients treated with early loaded implants using computerized tomography-guided surgical stents: Flapless versus conventional flapped surgery. Journal of Oral Rehabilitation, 34, 835-840. doi:10.1111/j.1365-2842.2007.01772.x

[12] Brodala, N. (2009) Flapless surgery and its effect on dental implant outcomes. The International Journal of Oral \& Maxillofacial Implants, 24, 118-125.

[13] Fortin, T., Bosson, J.L., Coudert, J.L. and Isidori, M. (2003) Reliability of preoperative planning of an image-guided system for oral implant placement based on 3-dimensional images: An in vivo study. The International Journal of Oral \& Maxillofacial Implants, 18, 886-893.

[14] Kim, J.I., Choi, B.H., Li, J., Xuan, F. and Jeong, S.M. (2009) Blood vessels of the peri-implant mucosa: A comparison between flap and flapless procedures. Oral Surgery, Oral Medicine, Oral Pathology, Oral Radiology and Endodontology, 107, 508-512. doi:10.1016/j.tripleo.2008.08.003

[15] Sclar, A.G. (2007) Guidelines for flapless surgery. Journal of Oral and Maxillofacial Surgery, 65, 20-32. doi:10.1016/j.joms.2007.03.017

[16] Orentlicher, G., Goldsmith, D. and Horowitz, A. (2010) Applications of 3-dimensional virtual computerized tomography technology in oral and maxillofacial surgery: Current therapy. Journal of Oral and Maxillofacial Surgery, 68, 1933-1959. doi:10.1016/j.joms.2010.03.013

[17] Hammerle, C.H., Stone, P., Jung, R.E., Kapos, T. and Brodala, N. (2009) Consensus statements and recommended clinical procedures regarding computer-assisted implant dentistry. The International Journal of Oral \& Maxillofacial Implants, 24, 126-131.

[18] Schneider, D., Marquardt, P., Zwahlen, M. and Jung, R.E. (2009) A systematic review on the accuracy and the clinical outcome of computer-guided template-based implant dentistry. Clinical Oral Implants Research, 20, 7386. doi:10.1111/j.1600-0501.2009.01788.x

[19] Misir, A.F., Sumer, M., Yenisey, M. and Ergioglu, E. (2009) Effect of surgical drill guide on heat generated from implant drilling. Journal of Oral and Maxillofacial Surgery, 67, 2663-2668. doi:10.1016/j.joms.2009.07.056

[20] Eli, I., Schwartz-Arad, D., Baht, R. and Ben-Tuvim, H. (2003) Effect of anxiety on the experience of pain in implant insertion. Clinical Oral Implants Research, 14, 115118. doi:10.1034/j.1600-0501.2003.140115.x

[21] Conrad, S.M., Blakey, G.H., Shugars, D.A., Marciani, R.D., Phillips, C. and White, R.P. (1999) Patients' perception of recovery after third molar surgery. Journal of Oral and Maxillofacial Surgery, 57, 1288-1294. doi:10.1016/S0278-2391(99)90861-3

[22] Van Gool, A. (1977) Clinical consequences of complaints and complications after removal of the mandibular third molar. International Journal of Oral Surgery, 6, 29-37. doi:10.1016/S0300-9785(77)80069-0

[23] Berge, T.I. and Gilhuus-Moe, O.T. (1993) Per- and postoperative variables of mandibular third-molar surgery by four general practitioners and one oral surgeon. Acta Odontologica Scandinavica, 51, 389-397. doi:10.3109/00016359309040590

[24] Valmaseda-Castellon, E., Berini-Aytes, L. and Gay-Escoda, 
C. (2001) Inferior alveolar nerve damage after lower third molar surgical extraction: A prospective study of 1117 surgical extractions. Oral Medicine, Oral Pathology, Oral Radiology and Endodontology, 92, 377-383. doi: $10.1067 /$ moe. 2001.118284

[25] Valmaseda-Castellon, E., Berini-Aytes, L. and Gay-Escoda, C. (2000) Lingual nerve damage after third lower molar surgical extraction. Oral Medicine, Oral Pathology, Oral Radiology and Endodontology, 90, 567-573. doi: $10.1067 /$ moe. 2000.110034

[26] Lindeboom, J.A. and van Wijk, A.J. (2010) A comparason of two implant techniques on patient-based outcome measures: A report of flapless vs. conventional flapped implant placement. Clinical Oral Implants Research, 21, 366-370. doi:10.1111/j.1600-0501.2009.01866.x

[27] Misch, K. and Wang, H.L. (2008) Implant surgery complications: Etiology and treatment. Implant Dentistry, 17, 159-168. doi:10.1097/ID.0b013e3181752f61

[28] Ellies, L.G. and Hawker, P.B. (1993) The prevalence of altered sensation associated with implant surgery. The International Journal of Oral \& Maxillofacial Implants, 8, 674-679.

[29] Bartling, R., Freeman, K. and Kraut, R.A. (1999) The incidence of altered sensation of the mental nerve after mandibular implant placement. Journal of Oral and Maxillofacial Surgery, 57, 1408-1412.

doi:10.1016/S0278-2391(99)90720-6

[30] Van Steenberghe, D., Lekholm, U., Bolender, C., Folmer, T., Henry, P., Herrmann, I., et al. (1990) Applicability of osseointegrated oral implants in the rehabilitation of partial edentulism: A prospective multicenter study on 558 fixtures. The International Journal of Oral \& Maxillofacial Implants, 5, 272-281.

[31] Tong, D.C. and Rothwell, B.R. (2000) Antibiotic prophylaxis in dentistry: A review and practice recommenddations. The Journal of the American Dental Association, 131, 366-374.

[32] Capuzzi, P., Montebugnoli, L. and Vaccaro, M.A. (1994) Extraction of impacted third molars: A longitudinal prospective study on factors that affect postoperative recovery. Oral Surgery, Oral Medicine, Oral Pathology, 77, 341-343. doi:10.1016/0030-4220(94)90194-5

[33] Siddiqi, A., Morkel, J.A. and Zafar, S. (2010) Antibiotic prophylaxis in third molar surgery: A randomized double-blind placebo-controlled clinical trial using split-mouth technique. International Journal of Oral and Maxillofacial Surgery, 39, 107-114. doi:10.1016/j.ijom.2009.12.014 